\title{
The Epidemiology of Snake Bite presenting to British Military Hospital Dharan during 1989
}

\author{
Lt Col B J Heap \\ MRCP, RAMC \\ Col G O Cowan \\ OBE, FRCP, LRAMC
}

Royal Army Medical College, Millbank, London SWIP 4RJ

SUMMARY: Fifty-eight cases of snake bite seen at the British Military Hospital, Dharan, Nepal during 1989 wer $\overrightarrow{0}$ studied prospectively. Data is presented on the epidemiology and outcome of snake bite in this area of lowland Nepat with details of the age and sex of patients, date and time of bite, delay in arrival at hospital, use of tourniquets, circumg stances of the bite, and snake identification.

Neurotoxicity due to envenomation was recorded in 11 patients. No case of coagulopathy was recorded. The overaî. case fatality was $5.2 \%$ but mortality amongst those exhibiting signs of neurotoxicity was $27.3 \%$.

\section{Introduction}

The incidence of snake bite is often underestimated in the rural tropics because of the lack of reliable epidemiological data (1). Snake bites present a problem in many areas of Nepal (2). Between 1980 and 1985 a baseline epidemiological study on snake bites and their management was reported from 12 districts of Nepal in collaboration with the World Health Organisation (WHO) Regional Office for South-East Asia (2). This study determined that 3,189 cases were treated and of these 144 died (case fatality rate $4.5 \%$ ). Individual patient records concerning 115 cases were collected and analysed retrospectively for epidemiological data.

The purpose of the current study was to examine prospectively all cases of snake bite seen at the British Military Hospital Dharan, a hospital situated in the south-east lowlands of Nepal, during the year 1989.

\section{Materials and Methods}

Information was sought from all patients attending the British Military Hospital Dharan who complained of being bitten by a snake. The data recorded included the age and sex of the patient, the date and time of the bite, the delay between bite and arrival at hospital, the part of the body bitten, circumstances of the bite and whether the snake was seen and identified. Particular note was made of the use of tourniquets. Signs and symptoms of envenoming were recorded.

\section{Results}

Of 58 cases seen with probable or definite snake bite, 40 were adults and 18 were children less than 15 years of age. There were 29 male and 29 female cases (Fig 1). Snake bite incidence was highest during the monsoon (May - September) (Fig 2). Bites were not confined to any particular period of the day or night but 35 of the bites occurred between $1400 \mathrm{hrs}$ and $2100 \mathrm{hrs}$ (Fig 3).
The individual's location at the time of the bite shown in Table 1. Table 2 lists the patient's activity at the time the snake bite took place.

The anatomical distribution of the bites was as fol lows: lower limb $30(51.7 \%)$, upper limb $26(44.8 \%$ head $2(3.5 \%)$. Of those bites on the lower limb 20 vigere on the foot or toes and of the upper limb bites 19 weresole the hand ( 13 on the right and 6 on the left).

The time taken for patients to reach hospital afte being bitten is shown in Table 3. The 3 patients seek aid more than twenty-four hours after being bitten dirs because of the complications of tourniquet application and not for treatment of bite per se. All other patients proceeded to the hospital without delay after havin being bitten.

Tourniquets had been applied in 54 of the 56 cases with a limb bite. In 25 cases the tourniquets were multiple.

Only 27 patients claimed to have seen the snake. these only 14 thought they could identify the snake, $\frac{1}{8}$ claiming bites by krait, 7 by cobra and 1 by pit viper. I․․ only 2 cases was the snake brought with the patient (on being a live snake) and both were identified as the cobre Naja naja.

Signs of neurotoxicity developed in 11 patients (Tab倨 4). There were no cases of bleeding diathesis. Nine patients had signs of neurotoxicity when first seen afte arrival at hospital. Of these 7 had tourniquets applieg and 2 were patients who although bitten on a limb had not used a tourniquet. All had arrived within 2 hours of being bitten. A tenth patient developed ptosis after as rival at hospital following the removal of a tournique which had been in position for 2 hours. One patient dief immediately on arrival prior to receiving medical ap tention having been bitten 14 hours previously. She had had a tourniquet applied after being bitten but this has been removed 3 hours later. 


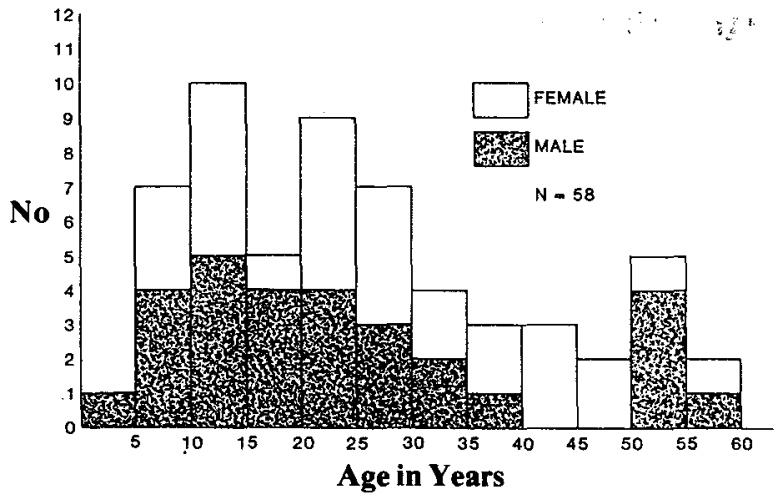

Fig 1. Distribution of snake bites with respect to age and sex.

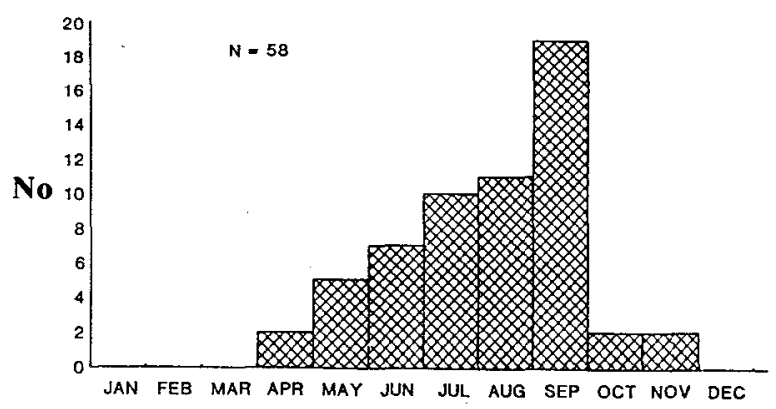

Fig 2. Distribution of snake bites with respect to month.

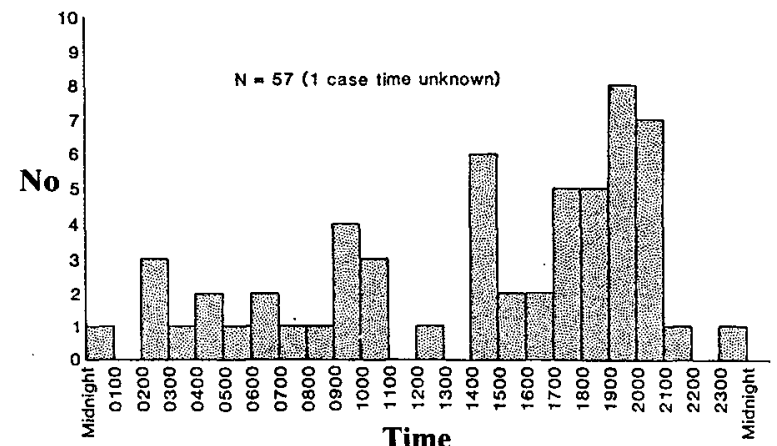

Fig 3. Distribution of snake bites with respect to time of day.
Table 1

Location at time of snake bite.

\begin{tabular}{lrr}
\hline & No & \multicolumn{1}{c}{$\%$} \\
\hline In a Field & 9 & 15.5 \\
In the Forest & 5 & 8.6 \\
On the Roadside & 5 & 8.6 \\
Inside the Home & 10 & 17.2 \\
Immediate surroundings of & & \\
the Home & 21 & 36.2 \\
Others & 8 & 13.8 \\
\hline
\end{tabular}

Table 2

Activity at time of snake bite.

\begin{tabular}{lrr}
\hline & No & $\%$ \\
\hline Collecting Firewood & 6 & 10.3 \\
Cutting Grass & 6 & 10.3 \\
Moving Cut Grass or Straw & 7 & 12.1 \\
In Bed & 3 & 5.2 \\
Preparing for Bed & 6 & 10.3 \\
Going out to Toilet & 10 & 17.2 \\
Walking & 8 & 13.8 \\
Digging & 4 & 6.9 \\
Others & 8 & 13.8 \\
\hline
\end{tabular}

Table 3

Delay from time of bite to arrival at hospital

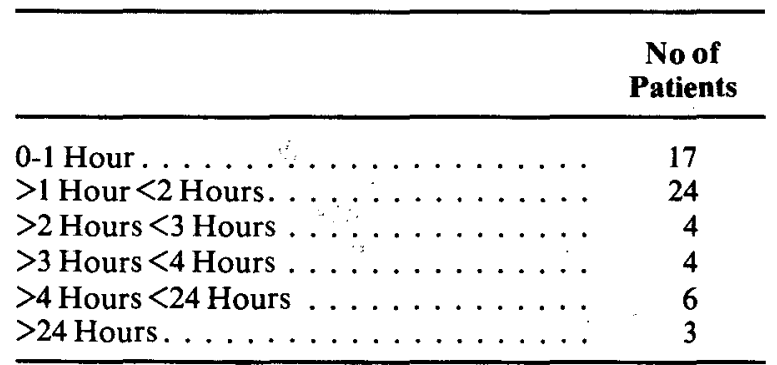


Table 4

Patients developing neurotoxicity.

\begin{tabular}{lcc}
\hline Patient & $\begin{array}{c}\text { Time from Bite to } \\
\text { Evidence of Toxicity }\end{array}$ & Outcome \\
\hline
\end{tabular}

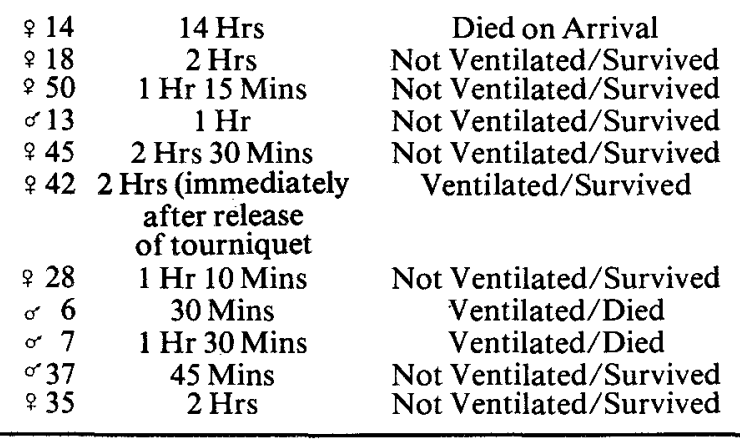

Patients with signs of neurotoxicity were treated with both polyvalent anti-snake venom serum manufactured by the Serum Institute of India and with neostigmine and atropine. Three patients required ventilatory support. Two (males age 6 and 7 years respectively) were ventilated after respiratory arrest which in both cases had occurred shortly after arrival at hospital and institution of treatment. Both died after developing intractable hypotension whilst being ventilated. One patient (female aged 42 years) was ventilated electively and made an uncomplicated recovery.

The overall case fatality for those patients who reached hospital was $5.2 \%$. In those patients demonstrating signs of neurotoxicity however there was a fatal outcome in $27.3 \%$.

\section{Discussion}

The findings that snake bite incidence is highest during the monsoon and bites are more frequent in the 5 to $40^{\circ}$ year age group are in agreement with the previous epidemiological study in Nepal (2).

Seventy-one per cent of patients presented within $2^{\infty}$. hours of the bite and $53.4 \%$ of bites took place within ores in the immediate surroundings of the home. This is ato variance with the previously published data where onlyo $30 \%$ reached hospital within 3 hours and only $11.3 \%$ were bitten in the home, and may reflect the proximity of the Military Hospital to the town of Dharan.

The use of tourniquets was almost universal. It is of interest that the 2 patients bitten peripherally who did $\vec{p}$ not use tourniquets had signs of neurotoxicity at pre $=\overrightarrow{\bar{\omega}}$ sentation but it is notable that adequate tourniquets applied soon after the bite did not prevent systemie envenomation and neurotoxicity in 7 patients.

The WHO study (2) reported a case fatality rate of $4.5 \%$. Our overall case fatality rate is comparable, but mortality in those developing signs of envenomation was very much higher despite the availability of adequate treatment and monitoring facilities. Young childrenw requiring ventilation after respiratory arrest appear to carry the poorest prognosis. Early elective respiratopy ventilation should be considered in children show signs of neurotoxicity.

\section{REFERENCES}

1. WARRELL D. A. Injuries, envenoming, poisongge and allergic reactions caused by animals. In: Oxf a d Textbook of Medicine, Weatherall D J, Ledinghing J G G and Warrell D A, eds. 2nd edition. Oxford University Press, 1987; 6.66-6.77.

2. Zoonotic disease control. Baseline epidemiologicab study on snake bite treatment and management: Nepal WHO Weekly Epidemiological Record 1987; 62: $319-320$. 